\title{
Neurons of a Limited Subthalamic Area Mediate Elevations in Cortical Cerebral Blood Flow Evoked by Hypoxia and Excitation of Neurons of the Rostral Ventrolateral Medulla
}

\author{
Eugene V. Golanov, John R. C. Christensen, and Donald J. Reis ${ }^{\dagger}$ \\ Division of Neurobiology, Department of Neurology and Neuroscience, Weill Medical College of Cornell University, New \\ York, New York 10021
}

\begin{abstract}
Sympathoexcitatory reticulospinal neurons of the rostral ventrolateral medulla (RVLM) are oxygen detectors excited by hypoxia to globally elevate regional cerebral blood flow (rCBF). The projection, which accounts for $>50 \%$ of hypoxic cerebral vasodilation, relays through the medullary vasodilator area (MCVA). However, there are no direct cortical projections from the RVLM/MCVA, suggesting a relay that diffusely innervates cortex and possibly originates in thalamic nuclei. Systematic mapping by electrical microstimulation of the thalamus and subthalamus revealed that elevations in rCBF were elicited only from a limited area, which encompassed medial pole of zona incerta, Forel's field, and prerubral zone. Stimulation (10 sec train) at an active site increased rCBF by $25 \pm 6 \%$. Excitation of local neurons with kainic acid mimicked effects of electrical stimulation by increasing rCBF. Stimulation of the subthalamic cerebrovasodilator area (SVA) with single pulses $(0.5 \mathrm{msec} ; 80$
\end{abstract}

$\mu \mathrm{A})$ triggered cortical EEG burst-CBF wave complexes with latency $24 \pm 5 \mathrm{msec}$, which were similar in shape to complexes evoked from the MCVA. Selective bilateral lesioning of the SVA neurons (ibotenic acid, $2 \mu \mathrm{g}, 200 \mathrm{nl}$ ) blocked the vasodilation elicited from the MCVA and attenuated hypoxic cerebrovasodilation by $52 \pm 12 \%(p<0.05)$, whereas hypercarbic vasodilation remained preserved. Lesioning of the vasodilator site in the basal forebrain failed to modify SVA-evoked rCBF increase. We conclude that (1) excitation of intrinsic neurons of functionally restricted region of subthalamus elevates rCBF, (2) these neurons relay signals from the MCVA, which elevate rCBF in response to hypoxia, and (3) the SVA is a functionally important site conveying vasodilator signal from the medulla to the telencephalon.

Key words: cerebral blood flow; neural regulation; electroencephalogram; hypoxia; thalamus; medulla
Cerebral hypoxia or ischemia elicits a rapid, patterned, autonomic response, which originates in the lower brainstem (Dampney et al., 1979; Guyenet and Brown, 1986) and includes sympathetic excitation, visceral and muscular vasoconstriction, bradycardia, and expiratory apnea (Dampney et al., 1979; Dampney and Moon, 1980; Guyenet and Brown, 1986; Sun and Reis, 1992; Sun et al., 1992). In addition, there is a widespread increase in regional cerebral blood flow ( $\mathrm{rCBF}$ ) without change in a cerebral metabolism [as evaluated by regional cerebral glucose utilization (rCGU)] and synchronization of the EEG (Underwood et al., 1992, 1994; Golanov and Reis, 1996; Golanov et al., 2000b;). The integrated response simulates the oxygenconserving (diving) reflex of mammals, an integrated pattern of responses considered to protect the brain from hypoxia by redirecting blood from the systemic to cerebral circulation in response to submersion or other stimuli activating the network (Butler, 1982; Blix and Folkow, 1983).

Much of the integrated response to cerebral ischemia/hypoxia results from excitation of reticulospinal sympathoexcitatory neurons of the rostral ventrolateral medullary nucleus (RVLM) (Pluta

\footnotetext{
Received Jan. 12, 2001; revised March 9, 2001; accepted March 14, 2001.

This work was supported by National Institutes of Health Grants NS36154 (E.V.G.) and HL18974 (D.J.R.). We express our deepest sympathy at the loss of our esteemed co-author and colleague, Donald J. Reis.

† Deceased, Nov. 1, 2000.

Correspondence should be addressed to Dr. Eugene Golanov, Division of Neurobiology, Department of Neurology and Neuroscience, Weill Medical College of Cornell University, 411 East 69th Street, New York, NY 10021. E-mail: egolano@mail.med.cornell.edu.

Copyright (C) 2001 Society for Neuroscience 0270-6474/01/214032-10\$15.00/0
}

et al., 1991; Sun and Reis, 1994a,b; Guyenet, 2000). These neurons are directly, selectively, rapidly, and reversibly excited in vitro or in vivo by hypoxia (Sun et al., 1992; Sun and Reis, 1993). Although the elevations in sympathetic, cardiovagal, or respiratory nerve activities are mediated over spinal or intramedullary pathways (Sun and Reis, 1999), hypoxic activation of RVLM neurons elevates rCBF and synchronizes the EEG, and this is not fully understood. Most likely, it is multisynaptic because the RVLM does not innervate the cerebral cortex (Ruggiero et al., 1989).

Recently we have functionally identified a region of the medullary reticular formation caudal to the RVLM and adjacent to the nucleus ambiguus termed medullary cerebrovasodilator area (MCVA), which may contain the first synapse of this neuronal network (Golanov et al., 2000b). However, because the effects on rCBF and EEG elicited by hypoxic or electrical stimulation of RVLM are bilateral and diffuse (Underwood et al., 1992; Golanov and Reis, 1994), it is likely that distal neurons in the chain arise from nuclei that diff usely project to the cortex. These would include areas such as the midline thalamic/centromedian complex (for review, see Jones, 1985; Price, 1995) and the basal forebrain (BF) (Saper and Loewy, 1980; Wenk et al., 1980; Eckenstein et al., 1988).

In this study, we sought to functionally identify regions of the diencephalon in which activation by microstimulation would, like hypoxia, elevate $\mathrm{rCBF}$ and interruption would block the responses elicited by stimulating the MCVA. We report that when excited electrically or with kainate, a small heretofore unrecognized area in a subthalamic region coincident with the Forel's field and medial pole of zona incerta (ZI) replicates the effects of excita- 
tion of the RVLM or MCVA. When the function of this area is interrupted, the cerebrovascular and electrocortical responses elicited from the MCVA are blocked. We have named the region the subthalamic cerebrovasodilator area (SVA) to emphasize function rather than topography.

\section{MATERIALS AND METHODS}

General procedures. Male Sprague Dawley rats were maintained in a thermally controlled $\left(27^{\circ} \mathrm{C}\right)$, light-cycled (lights on at 7:00 A.M.; lights off at 7:00 P.M.) environment with ad libitum access to water and lab chow. Anesthesia was induced by 5\% isoflurane in a gas mixture (nitrogen $80 \%$, oxygen $19.5 \%$, carbon dioxide $0.5 \%$ ) and maintained during surgery by $2.5 \%$ isoflurane. For the remainder of the experiment, isoflurane was maintained between 2 and $1.2 \%$. The depth of anesthesia was assured by the absence of a desynchronized EEG, variation in arterial pressure (AP), corneal reflexes, and hindleg flexing in response to pinch throughout the procedure. The experimental protocol was approved by the Institutional Animal Care and Use Committee of Weill Medical College of Cornell University.

Both femoral arteries and veins were cannulated with polyethylene catheters (outer diameter $=0.97 \mathrm{~mm}$ ). One arterial cannula was used to continuously measure AP, whereas the second was used to sample blood for measurement of blood gases. One venous catheter was used for continuous infusion of phenylephrine to maintain AP after spinal cord transection.

A tracheal cannula was inserted, wounds were closed, and animals were ventilated with a small animal respirator at 50-60 strokes per minute with the isoflurane/gas mixture. The stroke volume was adjusted to be equal (in milliliters) to the animal's weight in grams/100. The concentrations of $\mathrm{O}_{2}, \mathrm{~N}_{2}$, and $\mathrm{CO}_{2}$ were adjusted using calibrated flowmeters. Blood gases were measured several times during the experiment in $0.1 \mathrm{ml}$ samples of arterial blood by a blood gas analyzer. Blood gases were sampled and adjusted if necessary to keep them in the normal range for rat $\left(\mathrm{pH}, 7.46 \pm 0.023 ; \mathrm{Pa}_{\mathrm{O}_{2}}, 95.3 \pm 1.1 ; \mathrm{Pa}_{\mathrm{CO}_{2}}, 34.2 \pm 0.8\right)$ (Loeb and Quimby, 1989). Body temperature was monitored with a rectal probe connected to an electric thermometer-controlled heating pad, maintaining temperature at $37 \pm 0.6^{\circ} \mathrm{C}$.

After instrumentation, animals were placed in a stereotaxic frame with the bite bar adjusted at $-11 \mathrm{~mm}$ below the interaural line. The calvarium was exposed through a midline incision from the frontal bone to the atlanto-occipital junction, and the inferior half of the occipital bone was removed to expose the dorsal medulla. The calvarium was carefully thinned by a dental drill irrigated with saline at room temperature over two areas $3 \times 4 \mathrm{~mm}$ and centered $3 \mathrm{~mm}$ caudal to the frontal suture and $2.5 \mathrm{~mm}$ lateral to the sagittal suture and $5 \mathrm{~mm}$ caudal to frontal suture and $2 \mathrm{~mm}$ lateral to sagittal suture. Bone was removed until only the internal layer (lamina vitrea) remained. A stainless steel screw was inserted ipsilaterally extradurally $(0.5 \mathrm{~mm}$ rostral to the frontal and $1 \mathrm{~mm}$ lateral to the sagittal suture) to record EEG monopolarly. The indifferent lead was an electrode placed on the exposed neck muscles.

In some experiments the spinal cord was transected at the $\mathrm{C} 1-\mathrm{C} 2$ segment. To avert the acute elevation in AP associated with the procedure, $0.1 \mathrm{ml}$ of $2 \%$ procaine was injected locally just before sharp transection. Gelfoam was inserted into the cut, and an infusion of phenylephrine was started immediately $(1.3-6.4 \mu \mathrm{g} / \mathrm{min})$ to maintain AP (90-100 mmHg). Completeness of the transection was established histologically postmortem. Animals were allowed to stabilize for 30-40 min before the experiment was initiated.

Pulsatile AP was recorded using a strain gauge pressure transducer connected to an amplifier. EEG was recorded monopolarly and amplified and filtered $(1-100 \mathrm{~Hz})$. The respective signals were displayed simultaneously on channels of a chart recorder and also digitized and stored in a computer. $\mathrm{rCBF}$ was recorded with a laser-Doppler flowmeter (LDF) (PeriFlux PF3, Perimed). The probe $(0.8 \mathrm{~mm}$ in diameter) was mounted on a micromanipulator and placed, under magnification, just over the exposed lamina vitrea, avoiding large pial vessels (Golanov and Reis, 1994) that can generate false signals. The opening was filled with paraffin oil, and the probe was left in place for the remainder of the experiment. Flow values recorded with the time constant of $0.2 \mathrm{sec}$ were expressed in arbitrary units (perfusion units). Cerebrovascular reactivity was assessed immediately after positioning of the probe and randomly during the experiment by increasing the concentration of $\mathrm{CO}_{2}$ in the inhaled gas mixture to 5-7\% for $2 \mathrm{~min}$. The procedure, which increased $\mathrm{Pa}_{\mathrm{CO}_{2}}$ to 51-75 mmHg, but did not change $\mathrm{Pa}_{\mathrm{O}_{2}}(95-118 \mathrm{mmHg})$, rapidly elevated
rCBF by $60-90 \%$. If $\mathrm{CO}_{2}$ reactivity was lost during the course of an experiment, the experiment was discontinued and the animal was killed.

Electrical and chemical stimulation. To stimulate the thalamic area electrically or chemically, electrodes or micropipettes, respectively, were attached to the stereotaxic electrode holder. The coordinates of the bregma were taken as stereotaxic zero. An area of the brain from 3.5 to $6.5 \mathrm{~mm}$ caudal to bregma, $0.5-3 \mathrm{~mm}$ lateral, and from -4 to $-9 \mathrm{~mm}$ ventral to cortical surface was explored systematically for evoked changes in $\mathrm{rCBF}$.

The thalamic and medullary areas were stimulated through monopolar electrodes consisting of Teflon-insulated stainless steel wire $(150 \mu \mathrm{m})$ exposed only at the cut tip. An indifferent electrode was attached to the neck muscles. Cathodal square-wave pulses (5-150 $\mu \mathrm{A}, 0.5 \mathrm{msec}, 50-100$ $\mathrm{Hz}$ ) were generated by a square-wave stimulator and delivered to the electrodes through a constant current stimulus isolation unit. To determine the threshold of the reaction, the current was increased from $5 \mu \mathrm{A}$ in steps of $5 \mu \mathrm{A}$ until the maximum amplitude of reaction exceeded $2 \mathrm{SD}$ of baseline values. Electrolytic lesions were made through the same electrodes by a constant anodal current $(500 \mu \mathrm{A}, 30 \mathrm{sec})$.

To stimulate the medulla oblongata electrically or chemically, electrodes or micropipettes, respectively, were attached to the stereotaxic electrode holder and positioned over the calamus scriptorius at a $10^{\circ}$ posterior inclination. The coordinates of the calamus were taken as stereotaxic zero.

Intracerebral microinjections were made through glass capillary micropipettes with an outer diameter of $0.9 \mathrm{~mm}$. The pipette tip was broken back to $40-60 \mu \mathrm{m}$ in diameter. Drugs were injected manually in $20 \mathrm{nl}$ of solution by pressure during $15-20 \mathrm{sec}$. L-Glu was injected in the amount of $5 \mathrm{nmol}$ mixed with rhodamine beads to mark the site of injection. Kainate was microinjected as a fresh solution in saline $(\mathrm{pH} 7.3$ after adjustment with phosphate buffer) in the amount of 300 pmol.

At the end of each experiment, animals were killed by an intravenous bolus of $1.0 \mathrm{ml}$ of saturated $\mathrm{KCl}$. Brains were removed, frozen, and sectioned in $20 \mu \mathrm{m}$ slices in a cryostat microtome without fixation to prevent shrinking. Alternate slices were stained with thionine. Fluorescent images of unstained sections were superimposed on the images of corresponding stained sections using a computerized imaging system. Structures were identified microscopically, and their distribution in the brain was plotted.

Hypoxia and hypercarbia. Normocarbic hypoxic hypoxia was produced by adjusting the $\mathrm{O}_{2}$ content in the gas mixture to $\sim 10 \%$. The concentration of $\mathrm{CO}_{2}$ was increased appropriately (to $2-5 \%$ ) to maintain $\mathrm{Pa}_{\mathrm{CO}_{2}}$ within normal range (see Table 3). Animals were ventilated for $2 \mathrm{~min}$ at the lowered concentration of $\mathrm{O}_{2}$ before measurement of $\mathrm{rCBF}$ and blood gases. The decrease in AP that is usually observed under hypoxia (Marshall, 1987) was prevented by continuous infusion of phenylephrine $(2-10 \mu \mathrm{g} / \mathrm{min})$. Hypercarbia was created by ventilating animals with a gas mixture with the $\mathrm{CO}_{2}$ level increased to $\sim 5 \%$ for 2 min before measurements were taken.

Data analysis. After amplification and filtering (Cyberamp, Axon), AP, EEG, and rCBF signals were digitized (DT 2821 board, Data Translation) by a computer-based data acquisition system (DataWave Technologies) and stored on hard disk for further processing. The principal parameters of the responses (latency, amplitude, and duration) were extracted and averaged. Deviations of any parameter by $>2$ SDs from the baseline were established as the threshold of a reaction. rCBF measurements made by LDF were expressed as percentage changes over baseline.

To estimate changes in cerebrovascular resistance (CVR), we compared the ratio between $\mathrm{AP}$ and $\mathrm{rCBF}$ before and after each experimental procedure, calculated as a percentage of baseline values.

Fast Fourier transform analysis of EEG was performed over a $10 \mathrm{sec}$ epoch before and immediately after stimulation or microinjection of drugs. Resulting data were averaged across experimental animals. Statistical analysis of differences in the means before and after intervention was performed by using Student's paired $t$ test, or $t$ test for independent samples was used for different groups of animals. ANOVA was used for multiple comparisons. Results were assessed as significant at $p<0.05$.

\section{RESULTS}

\section{Subthalamic cerebrovasodilator area}

To localize sites in the thalamic area elevating rCBF, we systematically mapped the diencephalic area in 14 rats while recording rCBF, EEG, and AP (Fig. 1). The brain was stimulated every 200 $\mu \mathrm{m}$ with a $10 \mathrm{sec}$ train of pulses at $50 \mathrm{~Hz}$ and with a stimulus 


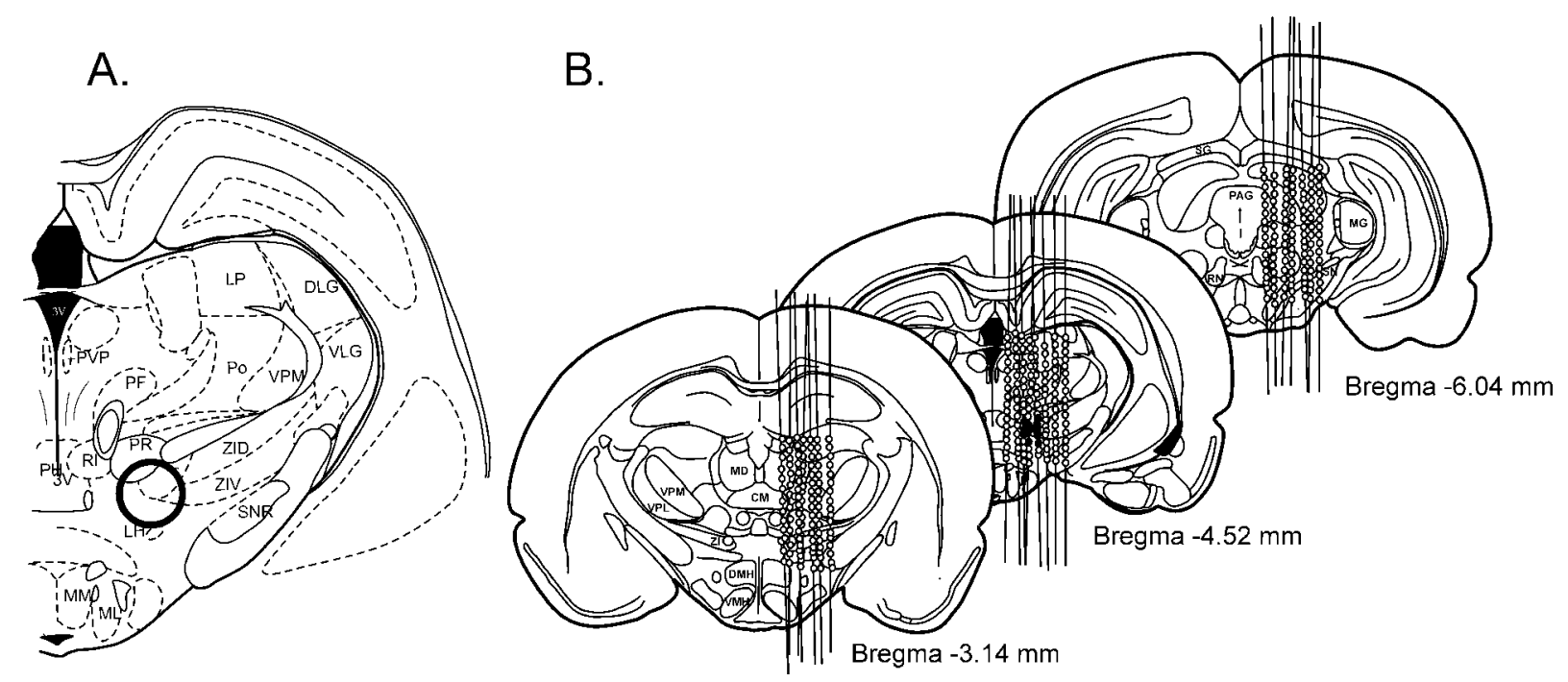

Figure 1. Cerebrovasodilator area (circled in bold) $(A)$ and distribution at three different levels of the rat brain $(B)$ (expressed as distances in millimeters caudal from bregma) of sites from which electrical stimulation increased cerebral blood flow (closed circles). Stimulation consisted of a 10 sec train ( 50 $\mathrm{Hz}$ at $50 \mu \mathrm{A}$ ). $B F$, Basal forebrain; $B S T$, bed nucleus of stria terminalis; $C M$, centrum medianum; $C p u$, caudate putamen; $D L G$, dorsal lateral geniculate nucleus; $D M H$, dorsomedial hypothalamic nucleus; $G P$, globus pallidus; $L P$, lateral posterior nucleus; $L H$, lateral hypothalamus; $M$, medial vestibular nucleus; $M C V A$, medullary cerebrovasodilator area; $M D$, mediodorsal nucleus, $M G$, medial geniculate nucleus; $M M$, medial mammillary nucleus; $M L$, lateral mammillary nucleus; $M P$, medial preoptic nucleus; $N T S$, nucleus tractus solitarius; $P A G$, pariaqueductal gray; $P H$, posterior hypothalamic area; $P F$, parafascicular nucleus; $P o$, posterior nucleus; $P R$, prerubral nucleus; $P T$, paratenial nucleus; $P V P$, paraventricular nucleus; $R I$, rostral interstitial nucleus; $R N$, red nucleus; $R O$, nucleus raphe obscurus; $S G$, superior colliculus; $S N R$, substantia nigra; $V L G$, ventrolateral geniculate nucleus; $V M H$, ventromedial hypothalamic nucleus; $V P L$, ventral posterolateral nucleus; $V P M$, ventral posteromedial nucleus; $Z I D$, dorsal zona incerta; $Z I V$, ventral zona incerta.

current of $30 \mu \mathrm{A}$. The thalamic area that was explored stretched from anterodorsal and anteroventral to parafascicular thalamic nuclei in the rostrocaudal direction, from midline to reticular nucleus in the lateral direction, and from the area immediately ventral to the lateral ventricle to the level of supramammillary nuclei in the dorsoventral direction. Electrode tracks and stimulation sites $(n=738)$ were reconstructed (see Materials and Methods for details). Bilateral elevations in $\mathrm{rCBF}$ were elicited only from a limited area in the caudal subthalamic area and included the medial pole of ZI, Forel's field, part of the prerubral zone, and rostral pole of deep mesencephalic nucleus. We designated this area the SVA.

\section{Stimulation of the SVA in non-spinalized (intact) rats}

Stimulation at an active site in spinal-intact rats (10 sec train) at a frequency of $50 \mathrm{~Hz}$ and a current of $30 \mu \mathrm{A}$ (average threshold for $10 \%$ increase in $\mathrm{rCBF}$ was $15 \pm 7 \mu \mathrm{A} ; n=24$ ) increased $\mathrm{rCBF}$ within 1-2 sec after onset of stimulation, which peaked at $25 \pm 6 \%$ $(n=32 ; p<0.01)$ in $20 \pm 4 \mathrm{sec}$ to recover $\sim 5-7$ min later (Fig. $2 A$, Table 1). An increase in rCBF was paralleled by a sharp drop in CVR of $20 \pm 3 \%(p<0.05)$ in $20 \mathrm{sec}$ and returned to baseline level simultaneously with $\mathrm{rCBF}$. In response to stimulation, AP changed biphasically: after an initial increase by $10 \pm 2 \%$ at $7 \mathrm{sec}$, it decreased by $6 \pm 1 \%$ at $14 \mathrm{sec}$ and returned to baseline in $20 \mathrm{sec}$. Along with the changes of $\mathrm{rCBF}$, the power of the 2-6 Hz EEG components immediately after stimulation increased by $66 \pm 23 \%$ $(p<0.05)$, whereas EEG amplitude remained unchanged $(768 \pm$ $134 \mu \mathrm{V}$ before and $698 \pm 168 \mu \mathrm{V}$ after; $p>0.05)$ (Fig. 3).

To evaluate the distribution of the SVA-evoked (10 sec train, 45 $\mu \mathrm{A}, 3 \times$ threshold, $100 \mathrm{~Hz}$ ) cerebrovasodilation over the cortex, we recorded $\mathrm{rCBF}$ over the contralateral occipital cortex and ipsilateral and contralateral to the stimulated site parietal cortex in the same animal. Maximum increase of rCBF was comparable at all three sites (occipital cortex, $44 \pm 5 \%$; parietal cortex contralateral $43 \pm 6 \%$ and ipsilateral $43 \pm 3 \% ; p>0.05$ (ANOVA); $n=3$ ).

Effects of electrical stimulation of the SVA were frequency and current dependent (Fig. 2C). The optimal stimulus frequency, established while stimulating with a constant stimulus current (50 $\mu \mathrm{A}$ ), was $\sim 100 \mathrm{~Hz}$. At $100 \mathrm{~Hz}$, the threshold for elevating $\mathrm{rCBF}$
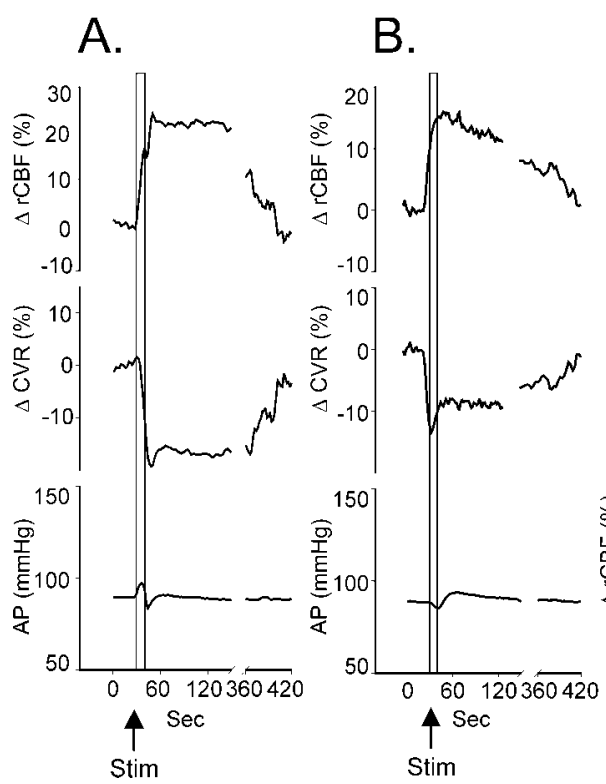

C.

Figure 2. Averaged responses in cortical rCBF (top trace), CVR (middle trace), and AP (bottom trace) in response to electrical stimulation (Stim; $10 \mathrm{sec}$ train, $50 \mathrm{~Hz}, 5 \times$ threshold current) of the SVA in spinal-intact rats $(A)$ and rats with transected spinal cord $(B)$ and dependency of the SVA-evoked rCBF responses on the frequency $(C)$ and intensity $(D)$ of stimulation. 


\begin{tabular}{|c|c|c|c|c|c|c|c|c|c|c|c|c|}
\hline Stimulation & $\begin{array}{l}\mathrm{LP} \text { rCBF } \\
(\mathrm{sec})\end{array}$ & $\begin{array}{l}\Delta \mathrm{rCBF} \\
(\%)\end{array}$ & $\begin{array}{l}\text { LP CVR } \\
(\mathrm{sec})\end{array}$ & $\begin{array}{l}\Delta \text { CVR } \\
(\%)\end{array}$ & $\begin{array}{l}\text { LP AP } \\
(\mathrm{sec})\end{array}$ & $\begin{array}{l}\Delta \text { AP } \\
(\%)\end{array}$ & $\begin{array}{l}\text { AP before } \\
(\mathrm{mmHg})\end{array}$ & $\begin{array}{l}\text { AP after } \\
(\mathrm{mmHg})\end{array}$ & $\begin{array}{l}\Delta \mathrm{EEG} \\
2.1-4.0\end{array}$ & $\begin{array}{l}\Delta \mathrm{EEG} \\
4.1-6.0\end{array}$ & Amplitude & Amplitude \\
\hline \multirow[t]{2}{*}{ SVA } & $20 \pm 4$ & $25 \pm 6$ & $20 \pm 4$ & $-20 \pm 3$ & $7 \pm 1$ & $10 \pm 2$ & & $98 \pm 3$ & $83 \pm 25$ & $49 \pm 19$ & $768 \pm 134$ & $698 \pm 168$ \\
\hline & & & & & $14 \pm 1$ & $-6 \pm 1$ & $90 \pm 2$ & $83 \pm 2$ & & & & \\
\hline \multirow[t]{2}{*}{ SVA spin } & $37 \pm 4$ & $17 \pm 2$ & $13 \pm 2$ & $-14 \pm 1$ & $9 \pm 1$ & $-4 \pm 1$ & & $85 \pm 6$ & $67 \pm 28$ & $42 \pm 16$ & $691 \pm 146$ & $726 \pm 189$ \\
\hline & & & & & $36 \pm 2$ & $6 \pm 1$ & $89 \pm 6$ & $94 \pm 8$ & & & & \\
\hline \multirow[t]{2}{*}{ Kainate } & & & & & & & & & & & & $781 \pm 127$ \\
\hline & $75 \pm 10$ & $46 \pm 8$ & $75 \pm 10$ & $-26 \pm 6$ & & $0 \pm 1$ & $92 \pm 5$ & $91 \pm 5$ & $76 \pm 32$ & $84 \pm 27$ & $659 \pm 152$ & \\
\hline
\end{tabular}

LP, Latent period.

was $12 \pm 7 \mu \mathrm{A}(n=6)$, and the response was graded with increasing stimulus currents. In all subsequent studies, the SVA was stimulated for $10 \mathrm{sec}$ at $100 \mathrm{~Hz}$, with stimulus currents $5 \times$ the threshold current. The optimum parameters of the stimulation are probably determined by the electrical properties of the SVA elements.

To establish the role of SVA neurons, we stimulated them selectively by microinjections of kainic acid (300 pmol, $20 \mathrm{nl}$; $n=3$ ). Microinjection of kainate into the SVA reversibly increased $\mathrm{rCBF}$ by $46 \pm 8 \%(p<0.05)$ over $\sim 75 \mathrm{sec}$ and, in parallel, reduced CVR by $-26 \pm 6 \%(p<0.01)$ (Fig. 4). AP did not change. Similar to electrical stimulation, chemical stimulation synchronized the EEG, increasing the power of the $2-6 \mathrm{~Hz}$ components by $80 \pm 19 \%(p<0.05)$, without changing the EEG amplitude $(659 \pm 152 \mu \mathrm{V}$ before and $781 \pm 127 \mu \mathrm{V}$ after; $p>0.1)$.

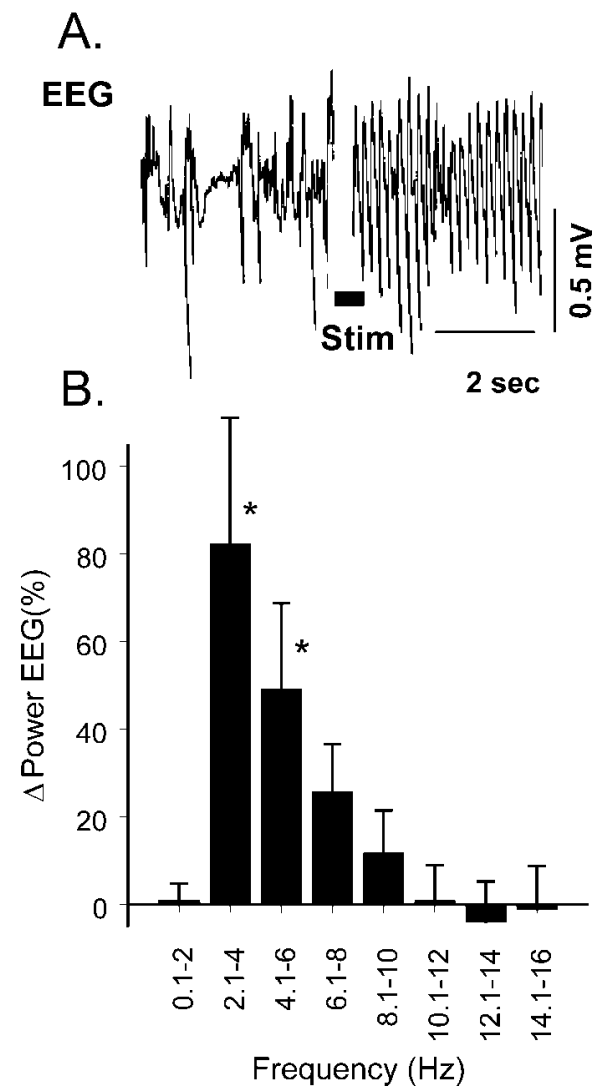

Figure 3. Sample of EEG response $(A)$ and changes in power of components of cortical EEG $(B)$ evoked by electrical stimulation of the SVA.

\section{Effects of stimulation of the SVA on rCBF, EEG, and AP in spinalized rats}

To exclude the possible effects of activation of autonomic nerves on $\mathrm{rCBF}$, we repeated stimulation of the SVA in spinalized rats $(n=4)$ in which AP was maintained by continuos infusion of phenylephrine. Electrical stimulation $(100 \mathrm{~Hz}, 52 \mu \mathrm{A}, 10 \mathrm{sec})$ of the SVA in spinalized rats increased $\mathrm{rCBF}$ by $17 \pm 2 \%(p<0.05$, $n=10)$ in $37 \mathrm{sec}$, which was accompanied by a decrease in CVR of $14 \pm 1 \%(p<0.01)$ in 13 sec. rCBF and CVR gradually returned to baseline level after 5-7 min. AP changed biphasically: after an initial decrease of $4 \pm 1 \%(p<0.05)$ at $9 \mathrm{sec}$, it increased by $6 \pm 1 \%(p<0.05)$ at $36 \mathrm{sec}$ after onset of stimulation (Fig. $3 B)$. EEG changed similarly to non-spinalized animals: the power of $2-6 \mathrm{~Hz}$ components increased by $52 \%$, whereas EEG amplitude remained stable.

\section{Effects of single pulse stimulation of the SVA on rCBF and EEG}

We also stimulated the SVA with single pulses $(0.5 \mathrm{msec}, 100 \mu \mathrm{A})$ while recording $\mathrm{rCBF}$ and EEG. Single pulse stimulation in $52 \%$ of the cases triggered short-lasting bursts $(5-8 \mathrm{sec})$ of synchro-

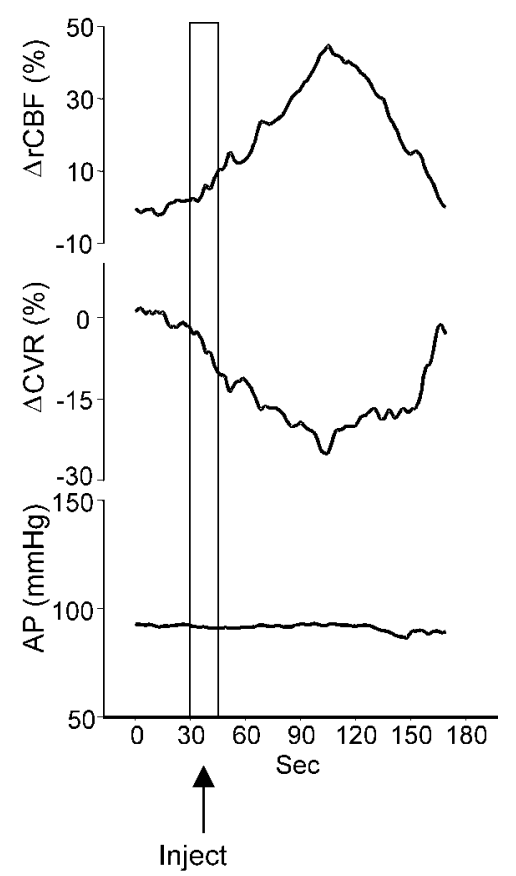

Figure 4. Averaged responses (three animals) of $\mathrm{rCBF}$ (top trace), CVR (middle trace), and AP (bottom trace) to microinjection of kainate (300 pmol, $20 \mathrm{nl}$ ) in the SVA. 


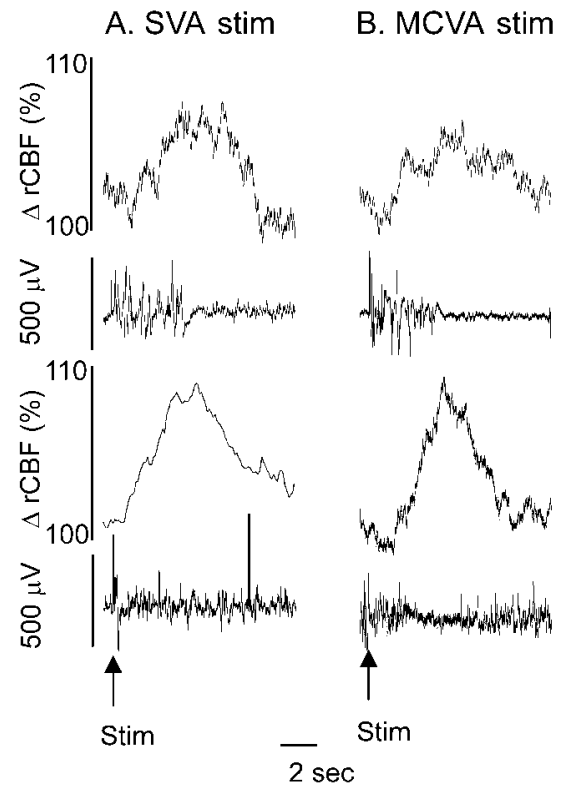

Figure 5. Cortical EEG burst-cerebrovascular wave complexes evoked by single pulse stimulation of the SVA $(A)$ and MCVA $(B)$. Single electrical pulses delivered to the SVA or MCVA triggered a burst of EEG activity (second trace) followed by an increase in rCBF (top trace). Averaging of burst-wave complexes (bottom traces) demonstrated a stable initial potential of EEG followed by highly reproducible cerebrovasodilation.

nized EEG activity accompanied by an increase in rCBF. Responses appeared bilaterally and synchronously with a latency between stimulus and burst onset of $24 \pm 2 \mathrm{msec}$. Individual responses to SVA stimulation consisted of an initial triphasic wave varying in configuration from burst to burst followed by high-amplitude low-frequency oscillations of varying duration (on average $5 \pm 3 \mathrm{sec}$ ). When averaged, evoked responses from the SVA consisted of an initial triphasic potential complex, accompanied by a wave of increase in rCBF of $5 \pm 1 \%$ in $4 \mathrm{sec}$ that returned to baseline level in 9-10 sec (Fig. 5).

These burst-wave complexes were identical to those observed in response to single pulse stimulation of the MCVA or FN as we demonstrated earlier. Single pulse stimulation of the MCVA triggered short bursts of synchronized EEG after a $24 \pm 2 \mathrm{msec}$ latency. The bursts lasted 6-7 sec and were accompanied by an increase in $\mathrm{rCBF}$ of up to $8 \%$, which lasted $\sim 10$ sec. The individual responses evoked by single pulse stimulation of the SVA or MCVA were similar to burst-wave complexes occurring spontaneously (Fig. 5).

\section{Effects of electrolytic lesion of the SVA on the effects of electrical stimulation of the MCVA}

To establish the possible role of the SVA in mediation of the cerebrovasodilatory effects of MCVA stimulation, we compared responses with train stimulation $(10 \mathrm{sec}, 0.5 \mathrm{msec}$ rectangular pulses, $50 \mathrm{~Hz}, 50 \mu \mathrm{A}$ ) of the MCVA before and after electrolytic lesion of the SVA. In five spinalized rats, a stimulating electrode was placed unilaterally into a functionally active site of the MCVA and into functionally defined regions of the SVA. After measuring the effects of MCVA stimulation on $\mathrm{rCBF}, \mathrm{CVR}$, and EEG, small bilateral electrolytic lesions were made in the SVA. After a recovery period of 20-30 min the MCVA was restimulated.

Before lesions, in agreement with our previous observations in response to stimulation of the MCVA in spinalized rats, $\mathrm{rCBF}$

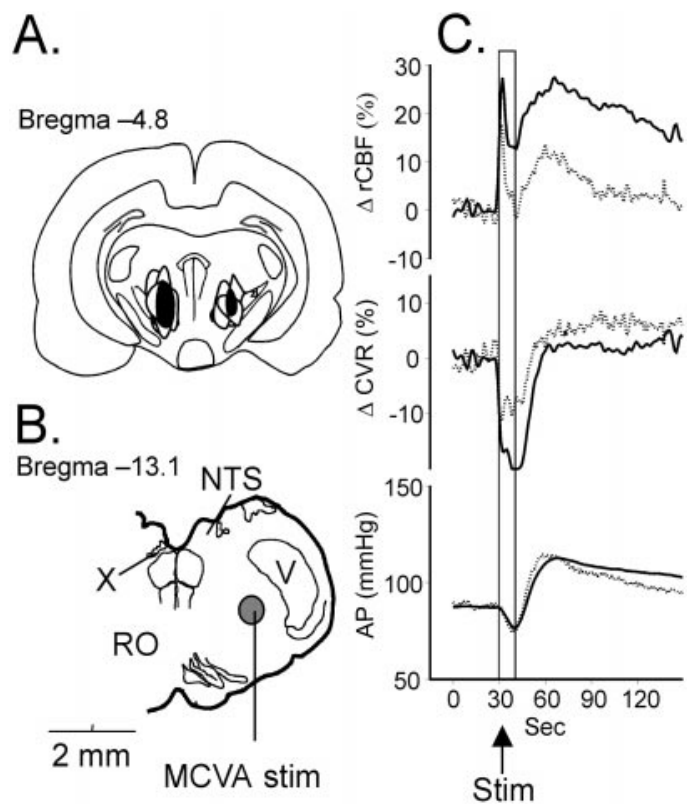

Figure 6. Effect of electrolytic lesion of the SVA on the increase in $\mathrm{rCBF}$ $(C)$, evoked by electrical stimulation of the MCVA in spinalized rats. Contours of lesions in different animals $(A)$ are superimposed, and the area common for all lesions is blackened. The site of the MCVA stimulation in $B$ is circled and filled with gray. $C$, Changes in $\mathrm{rCBF}$ [top trace and middle trace indicate changes in CVR; bottom trace indicates AP before (solid line) and after (dotted line) the lesion]. Abbreviations are as in Figure 1.

began to rise within $3 \mathrm{sec}$ of the stimulus onset and reached a maximum of $28 \pm 9 \%(n=21 ; p<0.01)$ at $35 \pm 5$ sec. It gradually returned to baseline within $3-5 \mathrm{~min}$. The CVR fell by $-21 \pm 9 \%(p<0.01)$ in 9 sec.

With stimulation, AP initially fell by $13 \pm 4 \%(p<0.05)$ at 10 $\mathrm{sec}$ and then reversed to rise to $29 \pm 9 \%$. It recovered 3-4 min later. The pressor component of the AP response results from the release of AVP sufficient to elevate AP in rats (Del Bo et al., 1983; Golanov and Reis, 1994; Golanov et al., 2000b).

Stimulation of the MCVA also synchronized the EEG by increasing the $4-6 \mathrm{~Hz}$ component power by $59 \%$ without a change in amplitude. EEG activity recovered in parallel with $\mathrm{rCBF}$.

Acute bilateral electrolytic lesions of the SVA (Fig. 6) did not affect resting $\mathrm{rCBF}$ or EEG. However, the lesions significantly attenuated the elevation of $\mathrm{rCBF}$ (to $14 \pm 5 \%$, decrease of $56 \%$ ), the reductions in CVR (to $-11 \pm 6 \%$, decrease of $48 \%)(p<$ 0.05 for both), and the synchronization of the EEG (decrease by $78 \% p<0.05$ ), without changing EEG amplitude. As depicted in Figure 6, the common area of destruction in all five animals was confined to the prerubral zone, Forel's field, and medial pole of zona incerta.

Control lesions $(n=3)$, which involved areas located dorsal to the SVA, did not affect responses to MCVA stimulation (Table 2).

\section{Effects of excitotoxic lesions of the SVA on hypoxic hypercarbic, and MCVA-evoked elevations of rCBF}

The observation that limited electrolytic lesion of the SVA significantly attenuated cerebrovascular effects of MCVA stimulation suggested that neurons of the SVA may be an important relay element of vasodilator signals generated by the MCVA and by oxygen sensors of RVLM. To test this hypothesis, we lesioned neurons of the SVA by microinjecting the excitotoxin ibotenic acid (Table 3). Rats were anesthetized and intubated, and mi- 


\begin{tabular}{|c|c|c|c|c|c|c|c|c|c|c|c|c|}
\hline MCVA stimulation & $\begin{array}{l}\text { LP rCBF } \\
(\mathrm{sec})\end{array}$ & $\begin{array}{l}\Delta \mathrm{rCBF} \\
(\%)\end{array}$ & $\begin{array}{l}\text { LP CVR } \\
(\mathrm{sec})\end{array}$ & $\begin{array}{l}\Delta \text { CVR } \\
(\%)\end{array}$ & $\begin{array}{l}\text { LP AP } \\
(\mathrm{sec})\end{array}$ & $\begin{array}{l}\Delta \mathrm{AP} \\
(\%)\end{array}$ & $\begin{array}{l}\text { AP before } \\
(\mathrm{mmHg})\end{array}$ & $\begin{array}{l}\text { AP after } \\
(\mathrm{mmHg})\end{array}$ & $\begin{array}{l}\Delta \mathrm{EEG} \\
2.1-4.0 \\
\mathrm{~Hz}(\%)\end{array}$ & $\begin{array}{l}\Delta \mathrm{EEG} \\
4.1-6.0 \\
\mathrm{~Hz}(\%)\end{array}$ & $\begin{array}{l}\text { Amplitude } \\
\text { EEG be- } \\
\text { fore }(\mu \mathrm{V})\end{array}$ & $\begin{array}{l}\text { Amplitude } \\
\text { EEG after } \\
(\mu \mathrm{V})\end{array}$ \\
\hline \multicolumn{13}{|l|}{ SVA lesion } \\
\hline Before lesion & $35 \pm 8$ & $28 \pm 4$ & $9 \pm 2$ & $-21 \pm 5$ & $38 \pm 3$ & $23 \pm 3$ & $87 \pm 2$ & $113 \pm 4$ & $78 \pm 21$ & $59 \pm 23$ & $652 \pm 187$ & $681 \pm 145$ \\
\hline After lesion & $30 \pm 9$ & $14 \pm 4^{*}$ & $8 \pm 2$ & $-11 \pm 4^{*}$ & $37 \pm 4$ & $17 \pm 3$ & $89 \pm 2$ & $103 \pm 2$ & $21 \pm 12^{*}$ & $14 \pm 7^{*}$ & $736 \pm 144$ & $665 \pm 158$ \\
\hline \multicolumn{13}{|l|}{ Control lesion } \\
\hline Before lesion & $37 \pm 7$ & $21 \pm 5$ & $10 \pm 2$ & $-15 \pm 3$ & $39 \pm 3$ & $21 \pm 3$ & $95 \pm 3$ & $116 \pm$ & $68 \pm 25$ & $67 \pm 24$ & $746 \pm 108$ & $689 \pm 167$ \\
\hline After lesion & $35 \pm 8$ & $28 \pm 5$ & $13 \pm 3$ & $-16 \pm 3$ & $35 \pm 3$ & $18 \pm 3$ & $98 \pm 3$ & $115 \pm$ & $76 \pm 19$ & $59 \pm 19$ & $643 \pm 189$ & $625 \pm 167$ \\
\hline
\end{tabular}

LP, Latent period. ${ }^{*} p<0.05$.

cropipettes were inserted into the area corresponding to the SVA. After testing responses to hypoxia, hypercarbia, and MCVA stimulation, ibotenate was microinjected ( $3 \mathrm{nmol}$ in $20 \mathrm{nl}$ ) into the SVA bilaterally, and animals were allowed to recover. They were reanesthetized $45 \mathrm{~d}$ later, and responses to stimulation of the MCVA, hypoxia, and hypercarbia were retested.

Excitotoxic lesions of the SVA practically abolished the increase in $\mathrm{rCBF}$ in response to MCVA stimulation, decreasing it by $>85 \%$ $(p<0.01)$ (Table 2). The hypoxic increase in $\mathrm{rCBF}$ was decreased by $51 \%(p<0.05)$. The increase in $\mathrm{rCBF}$ evoked by hypercarbia was reduced by $30 \%$; however, this decrease did not reach the level of significance $(p>0.05)$ and was similar in SVA- and non-SVAlesioned animals. Overall, the results were comparable to those observed after electrolytic lesion of the SVA (Fig. 7).

Subsequent histological examination of the area of excitotoxic lesion revealed extensive gliosis and disappearance of neuronal cell bodies in the area consisting of Forel's fields, the medial pole of the zona incerta, the rostral portion of the prerubral area, and the caudal pole of the lateral hypothalamic area.

Control lesions placed in the area dorsal to the SVA did not affect $\mathrm{rCBF}$ responses to MCVA stimulation and nonsignificantly $(p>0.05)$ reduced hypoxic and hypercarbic cerebral vasodilation.

\section{Effects of electrolytic lesion of basal forebrain on SVA- evoked elevations of rCBF}

Pathways ascending from the parvicellular reticular formation innervate the SVA and project further to the BF (Jones, 1995), chemical or electrical stimulation of which increases rCBF ipsilaterally to stimulation (Biesold et al., 1989; Lacombe et al., 1989; Vaucher et al., 1995). The rCBF increase evoked from BF is independent of metabolism (Kimura et al., 1990) and mediated by cholinergic mechanisms (Dauphin et al., 1991; Scremin et al., 1991; Sato and Sato, 1992; Zhang et al., 1995). We hypothesized that the BF might mediate the vasodilation evoked by the stimulation of the SVA.

To test this hypothesis, we electrolytically lesioned the vasoactive area of the BF on one side (Fig. 8) while we monitored ipsilateral hemisphere $\mathrm{rCBF}$ responses to the electrical stimulation of the SVA on the same side. Electrical stimulation of BF (10 sec train, $100-150 \mu \mathrm{A}, 0.5 \mathrm{msec}$ rectangular pulses, $50 \mathrm{~Hz} ; n=3$ ) triggered an increase in ipsilateral rCBF within 1-2 sec after the

Table 3. Effects of excitotoxic (ibotenic acid) lesion of the SVA on the effects of electrical stimulation of MCVA, hypoxemic hypoxia, and hypercarbia

\begin{tabular}{|c|c|c|c|c|c|}
\hline & $\Delta \mathrm{rCBF}(\%)$ & $\Delta \mathrm{CVR}(\%)$ & $\mathrm{P}_{\mathrm{O}_{2}}$ & $\mathrm{P}_{\mathrm{CO}_{2}}$ & $\mathrm{pH}$ \\
\hline \multicolumn{6}{|c|}{ MCVA stimulation } \\
\hline \multicolumn{6}{|c|}{ SVA lesion } \\
\hline Before & $31 \pm 7$ & $-25 \pm 6$ & $95 \pm 2$ & $34 \pm 2$ & $7.46 \pm 0.02$ \\
\hline After & $5 \pm 4$ & $-1 \pm 2$ & $102 \pm 3$ & $38 \pm 1$ & $7.43 \pm 0.02$ \\
\hline \multicolumn{6}{|c|}{ Control lesion } \\
\hline Before & $28 \pm 5$ & $-22 \pm 7$ & $98 \pm 2$ & $37 \pm 1$ & $7.44 \pm 0.03$ \\
\hline After & $26 \pm 7$ & $-21 \pm 3$ & $96 \pm 4$ & $31 \pm 2$ & $7.46 \pm 0.02$ \\
\hline \multicolumn{6}{|l|}{ Hypoxia } \\
\hline \multicolumn{6}{|l|}{ SVA lesion } \\
\hline Before & $91 \pm 16$ & $-45 \pm 10$ & $94 \pm 3$ & $34 \pm 2$ & $7.45 \pm 0.03$ \\
\hline After & $44 \pm 16$ & $-29 \pm 9$ & $27 \pm 7$ & $36 \pm 1$ & $7.44 \pm 0.02$ \\
\hline \multicolumn{6}{|c|}{ Control lesion } \\
\hline Before & $109 \pm 19$ & $-49 \pm 12$ & $95 \pm 2$ & $31 \pm 1$ & $7.46 \pm 0.02$ \\
\hline After & $98 \pm 26$ & $-47 \pm 11$ & $26 \pm 8$ & $36 \pm 2$ & $7.44 \pm 0.03$ \\
\hline \multicolumn{6}{|l|}{ Hypercarbia } \\
\hline \multicolumn{6}{|l|}{ SVA lesion } \\
\hline Before & $103 \pm 19$ & $-49 \pm 15$ & $89 \pm 4$ & $37 \pm 2$ & $7.44 \pm 0.02$ \\
\hline After & $73 \pm 15$ & $-45 \pm 12$ & $94 \pm 3$ & $56 \pm 8$ & $7.34 \pm 0.04$ \\
\hline \multicolumn{6}{|c|}{ Control lesion } \\
\hline Before & $134 \pm 21$ & $-58 \pm 13$ & $92 \pm 2$ & $34 \pm 3$ & $7.45 \pm 0.03$ \\
\hline After & $87 \pm 19$ & $-47 \pm 16$ & $97 \pm 3$ & $54 \pm 7$ & $7.36 \pm 0.04$ \\
\hline
\end{tabular}



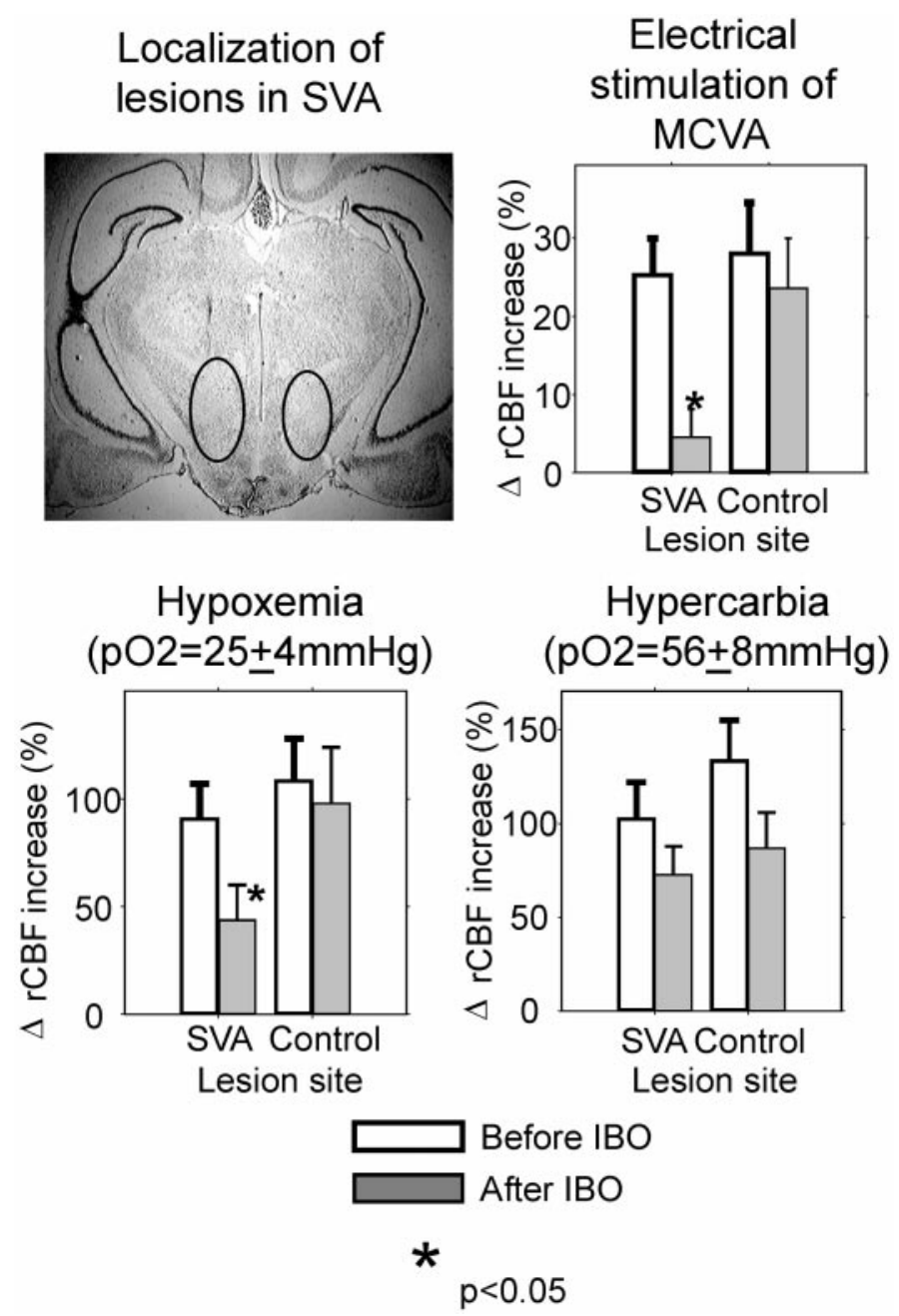

Figure 7. Effect of excitotoxic lesion of the SVA on the increase in $\mathrm{rCBF}$, evoked by hypoxia, hypercarbia, and electrical stimulation of the MCVA. Representative area with gliosis is circled on the photo of brain slice.

onset of stimulation. rCBF reached a maximum of $35 \pm 7 \%(p<$ $0.05)$ in $10 \mathrm{sec}$ and gradually returned to the baseline in $2-3 \mathrm{~min}$. Simultaneously with the increase in $\mathrm{rCBF}, \mathrm{CVR}$ significantly dropped by $28 \pm 9 \%(p<0.05)$ and recovered in parallel (Fig. 8$)$. Electrolytic lesion of the BF site, stimulation of which increased $\mathrm{rCBF}$, did not affect basal rCBF or amplitude of the $\mathrm{rCBF}$ responses to SVA stimulation. Maximum SVA-evoked rCBF increase was $19 \pm 5 \%$ before $\mathrm{BF}$ lesion, and after lesion it reached $23 \pm 6 \%(p>0.01)$.

\section{DISCUSSION}

The MCVA is a functional area located dorsocaudally to the RVLM-C1 area in the periambigual zone of the lateral reticular parvicellular area (Golanov et al., 2000b). Lesion of the MCVA reverses cerebrovasodilation evoked by RVLM excitation or by hypoxia (Underwood et al., 1992; Golanov and Reis, 1994). Electrical or chemical stimulation of the MCVA increases rCBF independently of metabolism in parallel with the decrease of CVR (Underwood et al., 1992; Golanov and Reis, 1994) and the increase in power of a $4-6 \mathrm{~Hz}$ component of cortical EEG (Golanov et al., 2000b).

To explore the ascending pathway relaying the vasodilator signal from the MCVA to the telencephalon, we systematically
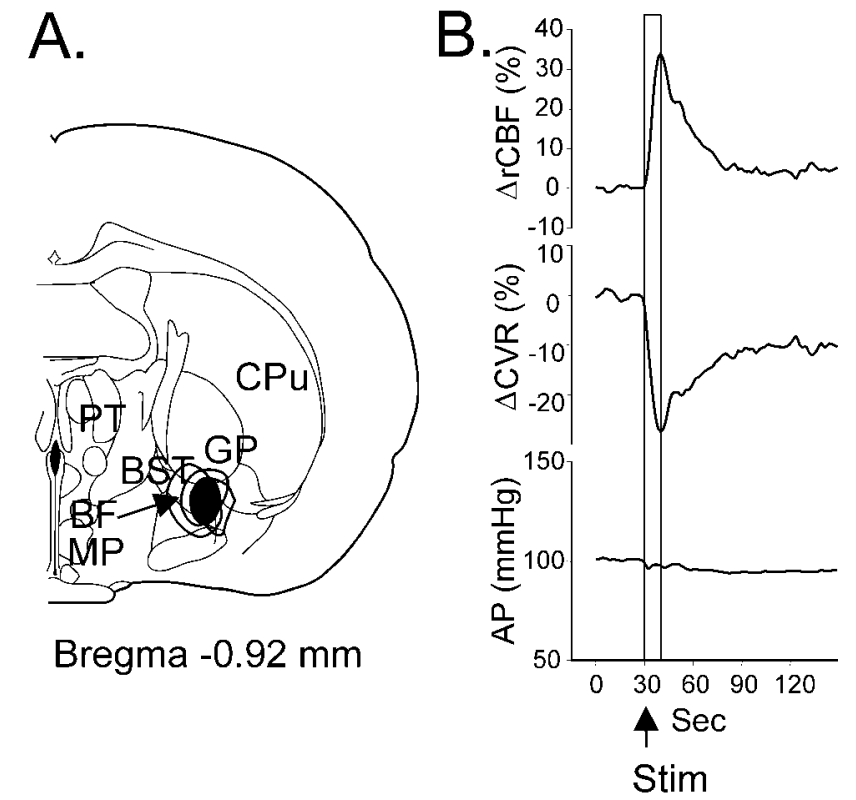

Figure 8. Localization of the lesion sites in the BF $(A)$ and effect of stimulation of these sites $(B)$ before the lesions on $\mathrm{rCBF}$ (top trace), CVR (middle trace), and AP (bottom trace). Contours of all lesions are superimposed, and the area common for all lesions is blackened. Abbreviations are as in Figure 1.

surveyed the thalamic region with electrical stimulation, searching for sites that are capable of increasing rCBF globally. We discovered that electrical or chemical simulation of the limited zone in the subthalamic area, which includes Forel's field, the medial pole of ZI and the rostral part of the prerubral area, increases $\mathrm{rCBF}$. We have termed the region the subthalamic vasodilator area (SVA) to stress a function, rather than topography, because it does not exactly correspond to a known nuclear group.

Data indicate that SVA might relay the cerebrovasodilator signal generated in the medulla. The elevation in rCBF elicited from the SVA with a $10 \mathrm{sec}$ stimulus train is comparable to the cerebral vasodilation evoked from RVLM (Underwood et al., 1992; Golanov and Reis, 1994) or the MCVA (Golanov and Reis, 1996; Golanov et al., 2000b). Similar to RVLM and the MCVA, the electrical stimulation of SVA elevated rCBF and decreased CVR. This response (1) appeared within seconds of the stimulus onset, (2) was graded with respect to stimulus intensity and shared a comparable frequency optima, 50-100 Hz, (3) was bilateral and diffuse, (4) was associated with the appearance of 4-6 Hz rhythm in the cortical EEG, and (5) was not affected by spinal cord transection. Unlike the RVLM or the MCVA, however, stimulation of the SVA in spinal-intact rats had a negligible effect on AP.

The effects of electrical stimulation of the SVA were fully mimicked by the chemical stimulation, indicating that excitation of SVA neurons is sufficient to produce cortical cerebrovasodilation and modify the EEG.

Electrical stimulation of the SVA with single pulses triggered cortical EEG bursts followed $\sim 1.2$ sec later by a monophasic elevation of the rCB-forming cerebrovascular wave (EEG burst$\mathrm{CW}$ ) complex appearing simultaneously and diffusely over both hemispheres. Similar burst-CW complexes appear spontaneously in deeply anesthetized animals (Golanov et al., 1994) and humans (Lam et al., 1995) and can be evoked by single pulse stimulation 
delivered to vasodilator sites of the MCVA or FN (Golanov and Reis, 1995). That the latency of burst-CW complexes evoked by single pulse stimulation of SVA $(\sim 24 \mathrm{msec})$ was shorter than those evoked by stimulation of the MCVA ( $\sim 33 \mathrm{msec}$ ) (Golanov and Reis, 1995) supports the contention that the SVA is a relay between the MCVA and more rostral sites. The difference of $\sim 9$ msec between latencies of burst-CW complexes evoked from the SVA and MCVA implies that a major delay of the signal occurs in the SVA projections to cortical neurons, which probably involve some diffuse system.

Selective lesioning of SVA neurons with bilateral excitotoxic lesions, which preserve fibers of passage, abolished the elevation of rCBF and EEG synchronization elicited by electrical stimulation of the MCVA. The effect is comparable to that of the electrolytic lesion of the SVA, indicating that local neurons rather than passing fibers convey vasodilator signals from the medulla. The block of the cerebrovasodilator effect of FN stimulation mediated by the MCVA (Glickstein et al., 1999; Golanov et al., 2000a) after excitotoxic lesion of the SVA (Glickstein et al., 1999) also supports the role of the SVA as the relay for the MCVAgenerated vasodilator signals.

The MCVA generates hypoxic cerebrovasodilator signal (Golanov et al., 2000b). In agreement with the suggested role of SVA as a relay of MCVA-generated signals, lesion of SVA reduced hypoxemic elevations of rCBF by $\sim 50 \%$, an impairment comparable to that elicited by lesions of the RVLM or MCVA (Underwood et al., 1994; Golanov and Reis, 1996; Golanov et al., 2000b).

Reversal of rCBF increase and EEG synchronization by electrolytic or excitotoxic lesions of the SVA was specific and did not result from the nonspecific brain damage, because lesions of comparable size placed dorsally to the SVA did not affect responses to stimulation of the MCVA, and hypercarbia-induced elevation of rCBF was not affected by SVA lesion.

Projections from the lateral reticular parvicellular nucleus, where the MCVA is located, reach the SVA within intermediate group of fibers ascending from the brain stem (Jones and Yang, 1985) independently of the medial forebrain bundle. These pathways project bilaterally diff usely to multiple thalamic nuclei, give collaterals to ZI (Jones and Yang, 1985; Vertes et al., 1986), issue projections to the lateral hypothalamus, basal ganglia, and $\mathrm{BF}$ (Ricardo, 1981), and are able to influence the entire forebrain. ZI-SVA projects further to the BF (Ricardo, 1981; Jones 1995) and makes it a good candidate to mediate cerebrovasodilator effects of SVA excitation. Electrical or chemical stimulation of the $\mathrm{BF}$ produces global and independent of metabolism increase in rCBF (Biesold et al., 1989; Lacombe et al., 1989; Kimura et al., 1990; Sato and Sato, 1992). However, failure of electrolytic lesion of $\mathrm{BF}$ to reverse the vasodilator effect of SVA stimulation refuted a possible relay role of the BF. It is still possible, however, that lesions were not large enough to completely destroy the whole BF area in our experiments.

Stimulation of the thalamic centrum medianum-parafascicular nucleus (CM-Pf) in rats elevates rCBF globally and independently of metabolism (Mraovitch et al., 1986; Mraovitch and Seylaz, 1987; Mraovitch et al., 1992; Goadsby et al., 1993). We did not observe significant changes in rCBF during exploratory stimulation of the CM-Pf area, probably because we used different exploratory stimulation parameters $(\sim 50$ vs $200 \mathrm{~Hz}$ and $\sim 50$ vs $\sim 150 \mu \mathrm{A}$ ) and isoflurane anesthesia [vs chloralose (Mraovitch et al., 1986; Mraovitch and Seylaz, 1987)], although it is known that neurogenic (primary) cerebrovasodilation is sensitive to the depth and nature of anesthesia (Iadecola and Reis, 1990; Iadecola et al., 1990).

Vasoactive sites in the CM-Pf of Mraovitch et al. (1986, 1987) are located just dorsally to the SVA. Although ventral sites were not explored in this work, stimulation of the CM-Pf produced the most significant functional correlated increase in $\mathrm{rCBF}$ and rCGU in the SVA (ZI-Forel's fields) (Mraovitch and Seylaz, 1987; Mraovitch et al., 1992), indicating functional activation of the SVA. It is reasonable to speculate that the CM-Pf and SVA may relate functionally.

Stimulation of the SVA, as well as the MCVA, simultaneously with rCBF increased the delta rhythm component of cortical EEG (Dossi et al., 1992; Amzica and Steriade, 1998). This may be related to the observed correlative increase of delta rhythm and cortical rCBF in humans (Hofle et al., 1997). Delta rhythm is thought to be generated by thalamocortical cells, when their hyperpolarization reaches a certain level (Steriade et al., 1997). It is therefore possible that the SVA may affect the activity of thalamocortical cells. It is also feasible that the appearance of delta rhythm in response to stimulation of the SVA, RVLM, FN, or MCVA is the so-called "paradoxical arousal," the phenomenon observed under isoflurane anesthesia in humans in response to strong stimuli normally triggering EEG desynchronization (Schwartz and Scott, 1978; Kochs et al., 1994; Litscher and Schwarz, 1999).

Hypoxemic hypoxia that is independent of the arterial chemoreceptors (Heistad et al., 1976; Miyabe et al., 1989) potently elevates rCBF independently of metabolism (Heistad and Kontos, 1983; Siesjö, 1987; Edvinsson et al., 1993). We have proposed that at least $50 \%$ of hypoxic cerebrovascular vasodilation is neurogenic (Underwood et al., 1994; Golanov and Reis, 1996). The neurogenic component is triggered by RVLM-C1 oxygen-sensing neurons in response to hypoxia (Sun and Reis, 1994b; Miyawaki et al., 1996), cerebral ischemia (Guyenet and Brown, 1986), or NaCN (Sun et al., 1992; Underwood et al., 1992; Golanov and Reis, 1994, 1996; Kawai et al., 1999). Bilateral lesions of the RVLM selectively (compared with hypercarbia) reduce the hypoxic vasodilation by $\sim 50 \%$ (Underwood et al., 1994; Golanov and Reis, 1996). Because the RVLM does not innervate the cerebral cortex (Ruggiero et al., 1989), the intracerebral pathway mediating cortical vasodilation is indirect, and the first synapse resides in the MCVA, which is innervated directly from RVLM (Golanov et al., 2000b). Excitation of the MCVA elicits changes in AP, rCBF, and EEG qualitatively identical to those elicited from RVLM. Bilateral lesions of the MCVA block the cerebrovascular and electrocortical responses to stimulation of RVLM as well as hypoxia-induced cerebrovasodilation. The vasodilator effects of MCVA excitation is relayed by the SVA to other brain areas.

In conclusion, we demonstrated that excitation of neurons of the limited area in the posterior subthalamus increases $\mathrm{rCBF}$ and the delta component of EEG, whereas their lesioning attenuates the increase in rCBF evoked by stimulation of the MCVA or by hypoxia. These findings allow us to hypothesize that the SVA is a key element of the endogenous brain system, which relays a cerebrovasodilator signal of different origin (hypoxic, activation, visceral) to the forebrain.

\section{REFERENCES}

Amzica F, Steriade M (1998) Electrophysiological correlates of sleep delta waves. Electroencephalogr Clin Neurophysiol 107:69-83.

Biesold D, Inanami O, Sato A, Sato Y (1989) Stimulation of the nucleus basalis of Meynert increases cerebral cortical blood flow in rats. Neurosci Lett 98:39-44. 
Blix AS, Folkow B (1983) Cardiovascular adjustments to diving in mammals and birds. In: The cardiovascular system, Section 2 (Renkin EM, Michel CC, eds), pp 917-945. Bethesda, MD: American Physiological Society.

Butler PJ (1982) Respiratory and cardiovascular control during diving in birds and mammals. J Exp Biol 100:195-221.

Dampney RA, Moon EA (1980) Role of ventrolateral medulla in vasomotor response to cerebral ischemia. Am J Physiol 239:H349-358.

Dampney RA, Kumada M, Reis DJ (1979) Central neural mechanisms of the cerebral ischemic response. Characterization, effect of brainstem and cranial nerve transections, and simulation by electrical stimulation of restricted regions of medulla oblongata in rabbit. Circ Res 45:48-62.

Dauphin F, Lacombe PM, Sercombe R, Hamel E, Seylaz J (1991) Hypercapnia and stimulation of the substantia innominata increase rat frontal cortical blood flow by different cholinergic mechanisms. Brain Res 553:75-83.

Del Bo A, Sved AF, Reis DJ (1983) Pressor effects of vasopressin released by fastigial nucleus stimulation in rat. J Hypertension 1[Suppl 2]:237-239.

Dossi RC, Nunez A, Steriade M (1992) Electrophysiology of a slow $(0.5-4 \mathrm{~Hz})$ intrinsic oscillation of cat thalamocortical neurones in vivo. J Physiol (Lond) 447:215-234.

Eckenstein FP, Baughman RW, Quinn J (1988) An anatomical study of cholinergic innervation in rat cerebral cortex. Neuroscience 25:457-474.

Edvinsson L, MacKenzie ET, McCulloch J (1993) Cerebral blood flow and metabolism. New York: Raven.

Glickstein SB, Golanov EV, Ilch CP, Reis DJ (1999) Stimulation of the subthalamic cerebrovasodilator area (SCA), a functionally restricted cerebral vasodilator region, protects against focal ischemic infarction. Soc Neurosci Abstr 25:2052.

Goadsby PJ, Seylaz J, Mraovitch S (1993) Noncholinergic, nonadrenergic cortical vasodilatation elicited by thalamic centromedianparafascicular complex. Am J Physiol 264:R1150-R1156.

Golanov EV, Reis DJ (1994) Nitric oxide and prostanoids participate in cerebral vasodilation elicited by electrical stimulation of the rostral ventrolateral medulla. J Cereb Blood Flow Metab 14:492-502.

Golanov EV, Reis DJ (1995) Vasodilation evoked from medulla and cerebellum is coupled to bursts of cortical EEG activity in rats. Am J Physiol 268:R454-R467.

Golanov EV, Reis DJ (1996) Contribution of oxygen-sensitive neurons of the rostral ventrolateral medulla to hypoxic cerebral vasodilatation in the rat. J Physiol (Lond) 495:201-216.

Golanov EV, Yamamoto S, Reis DJ (1994) Spontaneous waves of cerebral blood flow associated with a pattern of electrocortical activity. Am J Physiol 266:R204-R214.

Golanov EV, Christensen JR, Reis DJ (2000a) The medullary cerebrovascular vasodilator area mediates cerebrovascular vasodilation and electroencephalogram synchronization elicited from cerebellar fastigial nucleus in Sprague-Dawley rats. Neurosci Lett 288:183-186.

Golanov EV, Ruggiero DA, Reis DJA (2000b) Brainstem area mediating cerebrovascular and EEG responses to hypoxic excitation of rostral ventrolateral medulla in rat. J Physiol (Lond) 529:413-429.

Guyenet PG (2000) Neural structures that mediate sympathoexcitation during hypoxia. Respir Physiol 121:147-162.

Guyenet PG, Brown DL (1986) Unit activity in nucleus paragigantocellularis lateralis during cerebral ischemia in the rat. Brain Res 364:301-314.

Heistad DD, Kontos HA (1983) Cerebral circulation. In: Handbook of physiology, circulation, Vol III. Peripheral circulation and organ blood flow (Shepherd JT, Abboud FM, eds), pp 137-182. Bethesda, MD: American Physiological Society.

Heistad DD, Marcus ML, Ehrhardt JC, Abboud FM (1976) Effect of stimulation of carotid chemoreceptors on total and regional cerebral blood flow. Circ Res 38:20-25.

Hofle N, Paus T, Reutens D, Fiset P, Gotman J, Evans AC, Jones BE (1997) Regional cerebral blood flow changes as a function of delta and spindle activity during slow wave sleep in humans. J Neurosci 17:4800-4808.

Iadecola C, Reis DJ (1990) Continuous monitoring of cerebrocortical blood flow during stimulation of the cerebellar fastigial nucleus: a study by laser-Doppler flowmetry. J Cereb Blood Flow Metab 10:608-617.

Iadecola C, Springston ME, Reis DJ (1990) Dissociation by chloralose of the cardiovascular and cerebrovascular responses evoked from the cerebellar fastigial nucleus. J Cereb Blood Flow Metab 10:375-382.

Jones BE (1995) Reticular formation: cytoarchitecture, transmitters, and projections. In: The rat nervous system (Paxinos G, ed), pp 155-171. New York: Academic.

Jones BE, Yang TZ (1985) The efferent projections from the reticular formation and the locus coeruleus studied by anterograde and retrograde axonal transport in the rat. J Comp Neurol 242:56-92.

Jones EG (1985) The thalamus. New York: Plenum.

Kawai Y, Qi JG, Comer AM, Gibbons H, Win J, Lipski J (1999) Effects of cyanide and hypoxia on membrane currents in neurones acutely dissociated from the rostral ventrolateral medulla of the rat. Brain Res $830: 246-257$

Kimura A, Sato A, Takano Y (1990) Stimulation of the nucleus basalis of Meynert does not influence glucose utilization of the cerebral cortex in anesthetized rats. Neurosci Lett 119:101-104.

Kochs E, Bischoff P, Pichlmeier U, Schulte EJ (1994) Surgical stimulation induces changes in brain electrical activity during isoflurane/ nitrous oxide anesthesia. A topographic electroencephalographic analysis. Anesthesiology 80:1026-1034.

Lacombe PM, Sercombe R, Verrecchia C, Philipson V, MacKenzie ET, Seylaz J (1989) Cortical blood flow increase induced by stimulation of the substantia innominata in unanaesthetized rat. Brain Res 491:1-14.

Lam AM, Matta BF, Mayberg TS, Strebel S (1995) Change in cerebral blood flow velocity with onset of eeg silence during inhalation anesthesia in humans: evidence of flow-metabolism coupling? J Cereb Blood Flow Metab 15:714-717.

Litscher G, Schwarz G (1999) Is there paradoxical arousal reaction in the EEG subdelta range in patients during anesthesia? J Neurosurg Anesthesiol 11:49-52.

Loeb WF, Quimby FW (1989) The clinical chemistry of laboratory animals. New York: Pergamon.

Marshall JM (1987) Analysis of cardiovascular responses evoked following changes in peripheral chemoreceptor activity in the rat. J Physiol (Lond) 394:393-414.

Miyabe M, Jones Jr MD, Koehler RC, Traystman RJ (1989) Chemodenervation does not alter cerebrovascular response to hypoxic hypoxia. Am J Physiol 257:H1413-H1418.

Miyawaki T, Minson J, Arnolda L, Llewellynsmith I, Chalmers J, Pilowsky P (1996) AMPA/kainate receptors mediate sympathetic chemoreceptor reflex in the rostral ventrolateral medulla. Brain Res 726:64-68.

Mraovitch S, Seylaz J (1987) Metablolism-independent cerebral vasodilation elicited by electrical stimulation of the centromedianparafascicular complex rat. Neurosci Lett 83:269-274.

Mraovitch S, Lasbennes F, Calando Y, Seylaz J (1986) Cerebrovascular changes elicited by electrical stimulation of the centromedianparafascicular complex in rat. Brain Res 380:42-53.

Mraovitch S, Calando Y, Pinard E, Pearce WJ, Seylaz J (1992) Differential cerebrovascular and metabolic responses in specific neural systems elicited from the centromedian-parafascicular complex. Neuroscience 49:451-466.

Pluta R, Lossinsky AS, Mossakowski MJ, Faso L, Wisniewski HM (1991) Reassessment of a new model of complete cerebral ischemia in rats. Method of induction of clinical death, pathophysiology and cerebrovascular pathology. Acta Neuropathol (Berl) 83:1-11.

Price JL (1995) Thalamus. In: The rat nervous system (Paxinos G, ed), pp 629-648. San Diego: Academic.

Ricardo JA (1981) Efferent connections of the subthalamic region in the rat. II. The zona incerta. Brain Res 214:43-60.

Ruggiero DA, Cravo SL, Arango V (1989) Central control of the circulation by the rostral ventrolateral reticular nucleus: anatomical substrates. Prog Brain Res 81:49-79.

Saper CB, Loewy AD (1980) Efferent connections of the parabrachial nucleus in the rat. Brain Res 197:291-317.

Sato A, Sato Y (1992) Regulation of regional cerebral blood flow by cholinergic fibers originating in the basal forebrain. Neurosci Res $14: 242-274$

Schwartz MS, Scott DF (1978) Pathological stimulus-related slow wave arousal responses in the EEG. Acta Neurol Scand 57:300-304.

Scremin OU, Torres C, Scremin AM, O’Neal M, Heuser D, Blisard KS (1991) Role of nucleus basalis in cholinergic control of cortical blood flow. J Neurosci Res 28:382-390.

Siesjö BK (1987) Critical degrees of hypoxia and ischemia when cerebral function and metabolism are perturbed. In: Oxygen transport and utilization (Bryan-Brown C, Ayres SM, eds), pp 293-310. Fullerton, CA: Society of Critical Care Medicine.

Steriade M, Jones EG, McCormick DA (1997) Electrophysiologtical properties of thalamic neurons. In: Thalamus, pp 339-391. New York: Elsevier.

Sun M-K, Reis DJ (1992) Evidence nitric oxide mediates the vasodepressor response to hypoxia in sino-denervated rats. Life Sci 50:555-565.

Sun M-K, Reis DJ (1993) Hypoxic excitation of medullary vasomotor neurons in rats are not mediated by glutamate or nitric oxide. Neurosci Lett 157:219-222.

Sun M-K, Reis DJ (1994a) Central neural mechanisms mediating excitation of sympathetic neurons by hypoxia. Prog Neurobiol 44:197-219.

Sun M-K, Reis DJ (1994b) Hypoxia selectively excites vasomotor neurons of rostral ventrolateral medulla in rats. Am J Physiol 266:R245-R256.

Sun, M-K, Reis DJ (1999) Excitatory amino acid-mediated chemoreflex 
excitation of respiratory neurones in rostral ventrolateral medulla in rats. J Physiol (Lond) 492:559-571.

Sun M-K, Jeske IT, Reis DJ (1992) Cyanide excites medullary sympathoexcitatory neurons in rats. Am J Physiol 262:R182-R189.

Underwood MD, Iadecola C, Sved AF, Reis DJ (1992) Stimulation of $\mathrm{C} 1$ area neurons globally increases regional cerebral blood flow but not metabolism. J Cereb Blood Flow Metab 12:844-855.

Underwood MD, Iadecola C, Reis DJ (1994) Lesions of the rostral ventrolateral medulla reduce the cerebrovascular response to hypoxia. Brain Res 635:217-223.

Vaucher E, Borredon J, Seylaz J, Lacombe P (1995) Autoradiographic distribution of cerebral blood flow increases elicited by stimulation of the nucleus basalis magnocellularis in the unanesthetized rat. Brain Res 691:57-68.

Vertes RP, Martin GF, Waltzer R (1986) An autoradiographic analysis of ascending projections from the medullary reticular formation in the rat. Neuroscience 19:873-898.

Wenk H, Bigl V, Meyer U (1980) Cholinergic projections from magnocellular nuclei of the basal forebrain to cortical areas in rats. Brain Res 2:295-316.

Zhang F, Xu S, Iadecola C (1995) Role of nitric oxide and acetylcholine in neocortical hyperemia elicited by basal forebrain stimulation: evidence for an involvement of endothelia 1 nitric oxide. Neuroscience 69:1195-1204. 